\title{
How Credit Card Payments Increase Unhealthy Food Purchases: Visceral Regulation of Vices
}

\author{
MANOJ THOMAS \\ KALPESH KAUSHIK DESAI \\ SATHEESHKUMAR SEENIVASAN
}

\begin{abstract}
Some food items that are commonly considered unhealthy also tend to elicit impulsive responses. The pain of paying in cash can curb impulsive urges to purchase such unhealthy food products. Credit card payments, in contrast, are relatively painless and weaken impulse control. Consequently, consumers are more likely to buy unhealthy food products when they pay by credit card than when they pay in cash. Results from four studies support these hypotheses. Analysis of actual shopping behavior of 1,000 households over a period of 6 months revealed that shopping baskets have a larger proportion of food items rated as impulsive and unhealthy when shoppers use credit or debit cards to pay for the purchases (study 1). Follow-up experiments (studies 2-4) show that the vice-regulation effect of cash payments is mediated by pain of payment and moderated by chronic sensitivity to pain of payment. Implications for consumer welfare and theories of impulsive consumption are discussed.
\end{abstract}

$\mathrm{T}_{\mathrm{i}}^{\mathrm{h}}$ he past two decades have witnessed a rapid increase in obesity among U.S. consumers. According to the Center for Disease Control, 34\% of U.S. adults are obese, up from $23 \%$ in 1988. An additional $33 \%$ are overweight (Ogden et al. 2006). These results suggest that the consumption of unhealthy food is increasing and have prompted

Manoj Thomas is assistant professor of marketing at Cornell University, 353 Sage Hall, Ithaca, NY 14850 (mkt27@cornell.edu). Kalpesh Kaushik Desai is associate professor of marketing at State University of New York, Binghamton (kdesai@binghamton.edu). Satheeshkumar Seenivasan is a doctoral candidate at State University of New York, Buffalo (ss383 @ buffalo.edu). This article has benefited from stimulating discussions of related research papers in the behavioral marketing journal club at Cornell University. The authors gratefully acknowledge Robert Frank, Sachin Gupta, and the review team at $J C R$ for their helpful comments, and the Center of Relationship Marketing, State University of New York at Buffalo, for making the scanner panel data available for the field study. The authors thank Napatsorn Jiraporn and Bora Park for assisting with data collection and Barbara Drake for proofreading the manuscript.

Baba Shiv served as editor and Joel Huber served as associate editor for this article.

Electronically published October 6, 2010 several researchers to examine the factors that influence consumers' decisions to buy unhealthy food. Intriguingly, this period has also witnessed an increase in relatively painless forms of payment such as credit and debit cards (Humphrey 2004; Nilson Report 2007). The share of cash in consumer payments has fallen by a third, from $31 \%$ in 1974 to $20 \%$ in 2000. Cards are replacing cash as the preferred mode of payment; about $40 \%$ of purchases in 2006 were made using credit and debit cards. The average American carries 4.4 cards in his/her wallet. These trends raise important, but hitherto unaddressed, questions: Does the mode of payment influence consumers' ability to control their impulsive urges? Are consumers more likely to buy unhealthy food products when they pay by credit or debit cards than when they pay in cash? We address these questions from a psychological perspective in this research.

Our conceptualization and hypotheses draw on two distinct streams of research: the literature on impulsive consumption (Baumeister 2002; Hoch and Loewenstein 1991; Khan and Dhar 2006; Kivetz and Keinen 2006; Loewenstein 1996; Metcalfe and Mischel 1999; Raghunathan, WalkerNaylor, and Hoyer 2006; Ramanathan and Menon 2006; Rook 1987; Shiv and Fedorikhin 1999; Vohs and Heatherton 
2000; Wertenbroch 1998; Ubel 2009) and the literature on the psychological effects of different modes of payment (Feinberg 1986; Mishra, Mishra, and Nayakankuppam 2006; Prelec and Loewenstein 1998; Raghubir and Srivastava 2008, 2009; Soman 2001; Soman and Cheema 2002). Based on the first stream of literature, we suggest that some unhealthy food products trigger impulsive purchase urges because of the desire activated by emotive imagery and associated sensations. Consumers impulsively buy such products even though they consider the products to be unhealthy and experience regret after the purchase. Following Wertenbroch (1998; also see Kivetz and Keinen 2006), we characterize such food items as vice products. Based on the second stream of literature, we propose that mode of payment can influence decisions to purchase these vice products. Specifically, paying in cash feels more painful than paying by credit or debit card. This pain of paying in cash can curb impulsive responses and thus reduce the purchase of such vice products.

The notion that mode of payment can curb impulsive purchase of unhealthy food products is substantively important. The epidemic increase in obesity suggests that regulating impulsive purchases and consumption of unhealthy food products is a steep challenge for many consumers. Several factors contribute to this: the automatic nature of visceral responses to vice products (Shiv and Fedorikhin 1999), the depletability of cognitive resources that override these visceral responses (Vohs and Heatherton 2000), the chronicity of impulsive goals (Puri 1996; Ramanathan and Menon 2006), the belief in the "unhealthy = tasty" intuition (Raghunathan et al. 2006), and biases induced by contextual factors (Cheema and Soman 2008; Wansink 2006; Wansink and Chandon 2007). Given that many consumers struggle to regulate their impulsive responses, the finding that mode of payment could serve as a self-regulation tool has substantive relevance for consumer welfare.

Our conceptualization and empirical results augment the extant literature in several ways. First, we show that the effects of mode of payment are contingent on the type of product. Prior research has demonstrated that pain of payment affects the willingness to spend money (see Prelec and Loewenstein 1998); our results qualify this finding by demonstrating that relative to deliberative purchase decisions, impulsive purchase decisions are more likely to be influenced by pain of payment. This result calls for a more nuanced conceptualization of the effects of mode of payment on consumer behavior. Second, our results contribute to the debate on whether impulsive decisions to purchase unhealthy products can be characterized as rational choices. Some economists have argued that the decision to buy unhealthy food is a rational choice (see Ubel [2009] for a discussion of this debate). Per the rational choice model, consumers buy unhealthy food items because their utility from immediate consumption exceeds the disutility from long-term unhealthiness. The finding that purchases of impulsive products (e.g., cookies) are influenced by pain of payment while those of planned products (e.g., oatmeal) are not implies that these two types of purchase decisions cannot be characterized by the same rational choice model. This result supports Loewenstein's (1996) suggestion that descriptive choice models should incorporate the effects of visceral states. Finally, our results suggest that self-control is not entirely volitional; it can be facilitated or impeded by seemingly unrelated contextual factors that influence visceral responses.

\section{CONCEPTUAL FRAMEWORK}

\section{Impulsive Purchase of Vice Products}

Although consumption of unhealthy food products can be caused by several factors, such as faulty beliefs and lack of knowledge, impulsivity seems to be one of the, if not the most, influential antecedents of unhealthy food consumption. Most scholars who have attempted to conceptualize impulsivity concur that impulsive purchase decisions are based on spontaneous desires elicited by emotive imagery and associated sensations and that such decisions could be inconsistent with one's long-term plans and goals (Baumeister 2002; Hoch and Loewenstein 1991; Kivetz and Keinen 2006; Loewenstein 1996; Metcalfe and Mischel 1999; Rook 1987; Scott et al. 2008; Wertenbroch 1998). For example, Baumeister $(2002,670)$ defined impulsive purchasing as "behavior that is not regulated and that results from an unplanned spontaneous impulse. In particular, impulsive purchasing involves getting a sudden urge to buy something without advance intention or plan and then acting on that impulse without carefully or thoroughly considering whether the purchase is consistent with one's long range goals, ideals, resolves, and plans."

Adopting a similar perspective, in this paper we examine consumers' impulsive purchases of unhealthy food products. It is reasonable to assume that most people cherish long and healthy lives. So, when in a reflective frame of mind, most people would want to minimize their consumption of food items that they consider to be unhealthy. However, their purchase decisions are not always based on such deliberative thinking. When consumers encounter vice products-such as cookies, cakes, and pies-the emotive imagery and associated desire trigger impulsive purchase decisions (Loewenstein 1996; Shiv and Fedorikhin 1999; Wertenbroch 1998). These visceral factors can prod them to include such vice products in their shopping baskets even though they consider such products to be unhealthy.

Since the desire that triggers impulsive behavior is caused by visceral factors, it can be weakened by other aversive visceral factors. Aversive visceral responses, such as feelings of pain, can extinguish consumptive desires. With the extinction of desire, vice products no longer seem so appealing. Stated differently, the desire to consume a vice product is based on a visceral state, and it recedes with aversive visceral responses. This notion is consistent with Metcalfe and Mischel's (1999, 11) assertion that "internal activation of irrelevant hot nodes allows the diversion of considerable cognitive-affective energy and hence serves as 
an effective distracter." This line of reasoning implies that environmental factors that trigger feelings of pain can dissipate impulsive urges and thus curb impulsive purchases. We propose that mode of payment is one such environmental factor: pain of payment can reduce the pleasure of anticipated indulgence and thus curb impulsive purchases.

\section{Pain of Paying in Cash}

Several researchers have suggested that the mode of payment can influence pain of payment. Based on their model of hedonic mental accounting, Prelec and Loewenstein (1998) posited that paying in cash elicits greater pain than paying by other modes of payment even when the modes are normatively equivalent. Raghubir and Srivastava (2008) tested the effect of pain of payment on willingness to spend in several experiments. In one of their experiments (study 3 ), some participants were given a $\$ 50$ bill while others were given a $\$ 50$ scrip certificate - a certificate whose value is recognized by the payer and payee. Participants then responded to a simulated shopping study. The authors predicted that since paying by the scrip will feel less painful than paying in cash, participants will spend more with the scrip certificate. Consistent with their prediction, participants spent more when they were given scrip than when they were given an equivalent amount in cash. Several other studies offer converging empirical evidence for the proposition that cash payments feel different from other less vivid and emotionally more inert modes of payments (Mishra et al. 2006; Raghubir and Srivastava 2008, 2009; Soman 2001).

\section{Deliberative Purchase of Virtue Products}

Not all purchase decisions are based on spontaneous impulses. While purchase decisions of vice products - such as cookies, cakes, and pies-are influenced by spontaneous impulsive responses, purchase decisions of virtue products - such as fat-free yogurt and whole wheat bread-tend to be more deliberative. Previous research (e.g., Kross, Ayduk, and Mischel 2005) suggests that deliberative thinking can reduce the intensity of negative emotions. Further, since the purchase of virtue products is based on justifiable considerations ("I am buying something I need"), consumers might be able to rationalize or explain away the pain of payment. Based on this reasoning, we predict that while purchasing a virtue product such as fat-free yogurt, a consumer can explain away the pain of paying in cash. However, a consumer might not be able to explain away the pain of payment for a vice product since the purchase decision is based on a visceral response. Consequently, the pain of paying in cash is likely to have a larger effect on purchase decisions of vice than of virtue products.

To summarize our discussion thus far, the pain of paying in cash can weaken desires and thus curb impulsive purchases of vice products. However, the pain of paying in cash is less likely to influence purchase decisions of virtue products because such decisions tend to be based on more deliberative evaluations. This implies that the proportion of vice products relative to virtue products in the basket will change depending on the mode of payment. Based on this reasoning, we hypothesize:

H1: The number of unhealthy and impulsive food items (vice products) in the shopping basket will be lower when consumers pay in cash than when they pay by credit cards. Mode of payment will not influence the number of healthy and deliberative food items (virtue products) in the shopping basket.

Further, our conceptualization posits that pain of payment is caused by the form of payment and not by other mechanisms such as payment decoupling or time discounting of delayed payments. This implies that all types of cardscredit as well as debit-will reduce pain of payment and thereby increase the purchase of vice products. Like credit card payments, debit card payments are also less vivid and emotionally more inert than cash payments; therefore, they feel less painful. Hence, we expect that debit cards will also weaken impulse control. Formally,

H2: Both credit cards and debit cards will reduce pain of payment and thus increase purchases of vice products.

\section{Individual Differences in Sensitivity to Pain of Payment}

Previous research suggests that pain of payment is not only a situational factor, it is also an individual difference variable. Individuals differ in their sensitivity to pain of payment; some are chronically more sensitive to pain than others. Based on this premise, Rick, Cryder, and Loewenstein (2008) suggest that consumers can be identified as tightwads or spendthrifts. They label as tightwads those consumers whose affective reaction to spending may lead them to spend less than their more deliberative selves would prefer. In contrast, they label as spendthrifts those consumers who experience minimal pain of payment and, therefore, end up spending more than what they themselves would consider as normatively appropriate. Our conceptualization predicts that the vice-regulation effect of cash payments will vary across these two types of consumers. Relative to spendthrifts, tightwads would be more sensitive to pain of payment, and therefore pain of paying in cash will have a larger effect on their consumption of vice products. Formally,

H3: The vice-regulation effect of cash payments will be stronger for consumers who are more sensitive to pain of payment.

In the following sections, we describe the empirical studies conducted to test these hypotheses. 


\section{STUDY 1: MODE OF PAYMENT AND HEALTHINESS OF SHOPPING BASKET-A FIELD STUDY}

To seek preliminary evidence for the hypothesized effect of painless payment on consumption of unhealthy food items, we analyzed data from a large retailer that operates several grocery stores in the northeastern region of the United States. The data included information on what products each household in the panel purchased during their trips to the store and the prices of the products. More importantly, this data set is distinct from other typically used scanner panel data sets in that it provides information on whether each purchase was made using a credit card, debit card, or cash. Taking advantage of this unique aspect of the data set, we test whether consumers buy more impulsive and unhealthy food products when they pay by credit cards than when they pay in cash (hypothesis 1).

Further, this study also tests whether the proposed effect will manifest for both debit and credit cards or only for credit cards. Our conceptualization predicts that both debit and credit cards will increase the proportion of unhealthy and impulsive food products in the shopping basket, because the card payment format makes payments less vivid and thus reduces the pain of payment (hypothesis 2).

\section{Data}

Shopping Data. The data cover a period of 6 months (January to June) in the year 2003. We use a random sample of 1,000 loyal single-member households who primarily purchase from the chain stores for our analysis. We restrict our analyses to single-member households because in multimember households, it is not clear whether the observed effects are due to mode of payment or due to differences in shopping behaviors of individual members of the household. For example, a younger member of the household might always use credit cards while an older member might always use cash. In such a situation, it will be difficult to delineate the effect of mode of payment on purchases. By restricting our analyses to single-member households, we can avoid this confound. For these 1,000 households, we obtained data on what products they purchased during the 6-month period on each visit to the store and how they paid during the trip. Table 1 presents a summary of the relevant statistics for the sample. Note that about $41 \%$ of the transactions were paid by credit cards and $9 \%$ were paid by debit cards. Further, there is a lot of within-household variability in card usage; only $16 \%$ of the households used credit or debit cards on more than $90 \%$ of their shopping trips whereas $14 \%$ always paid in cash. A majority of the households switched between card and cash payments. Since we restrict our analysis to single-member households, these data offer us the opportunity to test our hypothesis on how mode of payment affects consumer behavior.

Our primary interest was in assessing whether the use of credit and debit cards increases the proportion of impulsive
TABLE 1

DESCRIPTIVE STATISTICS (STUDY 1)

\begin{tabular}{lc}
\hline \hline Variable & Mean values \\
\hline Average number of transactions at the focal retailer & 37.9 \\
Proportion of transactions paid with credit cards (\%) & 40.5 \\
Proportion of transactions paid with debit cards (\%) & 8.9 \\
Proportion of households paying with credit or debit & \\
$\quad$ cards on more than 90\% of transactions (\%) & 15.9 \\
Proportion of households not using credit or debit & \\
$\quad$ card at all (\%) & 13.9 \\
Average basket size, cash purchases (\$) & 37.9 \\
Average basket size, credit card purchases (\$) & 67.6 \\
Average basket size, debit card purchases (\$) & 60.1 \\
Average basket impulsiveness (1-9 scale) & 4.1 \\
Average basket unhealthiness (1-9 scale) & 4.4 \\
\hline
\end{tabular}

NOTE.-Basket size refers to the amount of money spent on the 100 food items included in this study.

vice products in the shopping basket. Since impulsiveness of a product is easier to assess in the context of food categories, we selected 100 major food categories (baby food, tea, gelatin, meat, etc.) based on the sales of the products. These 100 categories were selected only on the basis of their sales and accounted for $73 \%$ of the food sales in our sample. Thus, these 100 categories represent the types of food products consumers typically buy. We used the same category labels that the retail store management uses to organize and display the products on the retail shelves.

Survey for Impulsiveness and Healthiness Ratings of Categories. Our analyses required the ratings of these 100 categories on the impulsiveness-planned and healthy-unhealthy scales. Since these ratings were not available in the data set, we obtained them through a survey. Note that our interest is in perceptions of unhealthiness rather than actual unhealthiness of food items. If a consumer does not perceive a product as unhealthy, then she is unlikely to consider it as a vice product and experience postpurchase regret. Seventy-eight undergraduate students at a northeastern U.S. university were asked to rate each of these 100 food categories. To ensure that the results were not biased by a repeatedmeasure design, we asked about one-half of the pretest survey participants to rate the categories on impulsiveness while the other half were asked to rate each category on healthiness. One group of participants $(n=37)$ were asked to rate each category on planned-impulsive purchase continuum. Specifically, they were informed that "an impulsive product is one that is usually purchased without prior planning. Even when they do not plan to buy the product, consumers often buy such products spontaneously when they are in a store. In contrast, planned products are based on prior deliberation. Consumers come into the store with the intention of buying such products." Participants evaluated each of the 100 categories on a 9-point scale anchored at 1 $=$ Planned and $9=$ Impulsive. Participants' responses were 
averaged to compute the average impulsiveness rating for each category. Beans, barley, rice, baby food, vegetables, milk, and meat were some of the less impulsive categories, and ice cream, candies, cookies, gum, donuts, potato chips, and pudding were some of the more impulsive product categories in the list of 100 categories.

The second group of participants evaluated each of the 100 categories on a 9-point scale anchored at $1=$ Healthy and $9=$ Unhealthy. Their responses were also averaged to compute the average unhealthiness rating for each category. As expected, impulsiveness and unhealthiness ratings collected from separate groups of respondents were highly correlated $(r=.59, p<.01)$; categories that were rated as impulsive were also rated as unhealthy.

\section{Analysis}

Dependent Variables. To test the robustness of our results, we created two separate indices for measuring the unhealthiness and impulsiveness of a shopping basket-a simple-average index and a dollar share weighted-average index. The first index, the average unhealthiness, is based on a simple average of the category level unhealthiness scores for all the categories in the consumer's basket during a shopping trip. For instance, if a shopper has 16 categories in the basket, then the average unhealthiness measure is constructed by summing up the unhealthiness ratings of all these 16 categories and dividing the sum by 16 . The second index is constructed using share-weighted sum-of-categorylevel scores where the weight is dollar share of that category in the basket. Under this measure, if a category accounts for $60 \%$ of the total basket value, then the unhealthiness rating of that category is given a weight of 0.6 in the computation of total basket unhealthiness. While the first index is influenced by only the number of unhealthy products, the second one captures the relative amount of money spent on unhealthy products. We used these two indices to test whether mode of payment affects the number of unhealthy categories purchased, the money spent on unhealthy products, or both. For example, if card payments induce consumers to buy more expensive brands without affecting the number of categories, then we expect the mode of payment to influence only the weighted-average index. These two indices were highly correlated (0.94). Since we are concerned with the unhealthiness as well as the impulsiveness of the basket, these two indices were created for both ratings - the impulsiveness ratings and the unhealthiness ratings. Thus, we created four different indices to test the effect of mode of payment on purchases: average impulsiveness, weighted-average impulsiveness, average unhealthiness, and weighted-average unhealthiness.

Independent Variables. Next, we regressed each of the four indices separately on the mode of payment controlling for some trip-level variables. Our model specification for a household $h$ in shopping trip $t$ is as follows:

$$
\begin{aligned}
\text { Index }_{h t}=\beta_{0} & +\beta_{1} \text { Creditcard_Payment }_{h t} \\
& +\beta_{2} \text { Debitcard_Payment }_{h t} \\
& +\beta_{3} \text { Basket_Size }_{h t} \\
& +\beta_{4} \text { Last_Basket_Size }_{h t} \\
& +\beta_{5} \text { Weekend }_{h t} \\
& +\xi_{h t} .
\end{aligned}
$$

Our focal variables here are the credit card and debit card payment modes that are operationalized as binary dummy variables. Specifically, the credit card variable is set to 1 for the trips where the consumer paid using a credit card and 0 for the trips where they used other modes of payment. The debit card variable was operationalized likewise. Since mode of payment is likely to be correlated with other variables that influence purchase decisions, we control for the available trip-specific variables. We control for basket size on the current trip as well as the previous trip, both measured by the value of the shopping basket. We also control for whether the shopping day is a weekend or weekday using a dummy variable which is set to 1 for weekends. The model was run using clustered regression (for repeated measurements) in SAS separately for each of the indices.

\section{Results}

The results of the empirical analyses are presented in table 2. Our results are consistent with hypotheses 1 and 2 and indicate that both credit and debit card payments have a significant positive impact on the impulsiveness and unhealthiness of the basket. These results suggest that consumers are more likely to purchase impulsive and unhealthy food items when they pay with credit or debit cards on the shopping trip. Further, the results are consistent across both the number-based and value-based measures of basket impulsiveness and unhealthiness.

The parameters for other predictor variables are generally consistent with our expectations and thus confirm the validity of the estimated parameters. The basket sizes of the current and the last shopping trips have a positive effect, implying that larger-basket shoppers are likely to be more susceptible to impulsive purchase of unhealthy products. This finding is consistent with previous research (Ainslie and Rossi 1998; Bell and Lattin 1998), which suggests that basket size could be a proxy measure of individual differences in pain of payment; consumers who experience more (less) pain of paying tend to have fewer (more) items in their shopping baskets. The day of shopping has a significant negative effect indicating that consumers shopping on weekends are less likely to be impulsive. This could be because of the shopping list effect: weekend shopping trips tend to be based on shopping lists, and therefore purchases on such trips are less susceptible to impulsive urges.

To examine the role of impulsiveness, we tested whether 
TABLE 2

RESULTS OF ACTUAL SHOPPING BEHAVIOR ANALYSES (STUDY 1)

\begin{tabular}{|c|c|c|c|c|}
\hline \multirow[b]{2}{*}{ Parameter estimates (SE) } & \multicolumn{4}{|c|}{ Dependent variable } \\
\hline & $\begin{array}{c}\text { Average } \\
\text { impulsiveness }\end{array}$ & $\begin{array}{l}\text { Weighted-average } \\
\text { impulsiveness }\end{array}$ & $\begin{array}{c}\text { Average } \\
\text { unhealthiness }\end{array}$ & $\begin{array}{l}\text { Weighted-average } \\
\text { unhealthiness }\end{array}$ \\
\hline Intercept & $\begin{array}{l}3.901^{\star \star *} \\
(.015)\end{array}$ & $\begin{array}{l}3.888^{\star \star *} \\
(.015)\end{array}$ & $\begin{array}{l}4.285^{\star \star \star} \\
(.017)\end{array}$ & $\begin{array}{l}4.337^{\star \star \star} \\
(.017)\end{array}$ \\
\hline Credit card payment & $\begin{array}{l}.129^{\star \star *} \\
(.016)\end{array}$ & $\begin{array}{l}.150^{\star \star \star} \\
(.017)\end{array}$ & $\begin{array}{l}.107^{\star \star \star} \\
(.018)\end{array}$ & $\begin{array}{l}.155^{\star \star \star} \\
(.019)\end{array}$ \\
\hline Debit card payment & $\begin{array}{l}.154^{\star \star \star} \\
(.026)\end{array}$ & $\begin{array}{l}.164^{\star \star \star} \\
(.028)\end{array}$ & $\begin{array}{l}.156^{\star \star \star} \\
(.030)\end{array}$ & $\begin{array}{l}.176^{\star \star \star} \\
(.031)\end{array}$ \\
\hline Basket size & $\begin{array}{l}.001^{* \star *} \\
(.0001)\end{array}$ & $\begin{array}{l}.002^{\star \star \star} \\
(.0001)\end{array}$ & $\begin{array}{l}.002^{\star \star \star} \\
(.0002)\end{array}$ & $\begin{array}{l}.004^{\star * \star} \\
(.0001)\end{array}$ \\
\hline Last basket size & $\begin{array}{l}.003^{\star \star} \\
(.001)\end{array}$ & $\begin{array}{l}.004^{* * *} \\
(.001)\end{array}$ & $\begin{array}{l}.004^{\star \star \star} \\
(.002)\end{array}$ & $\begin{array}{l}.004^{* \star *} \\
(.002)\end{array}$ \\
\hline Weekend & $\begin{array}{l}-.110^{* * *} \\
(.014)\end{array}$ & $\begin{array}{l}-.118^{\star * \star} \\
(.015)\end{array}$ & $\begin{array}{l}-.097^{\star \star \star} \\
(.016)\end{array}$ & $\begin{array}{l}-.097^{\star * \star} \\
(.017)\end{array}$ \\
\hline Pseudo $R^{2}$ & .205 & .293 & .273 & .492 \\
\hline
\end{tabular}

${ }^{* *} p<.05$

${ }^{\star \star \star} p<.01$

the effect of credit cards on the unhealthiness of the basket is stronger for very impulsive products than for planned products. We split the products into two groups based on their ratings on the planned-impulsive scale. Categories with ratings greater than or equal to 6 on the 9-point scale were considered as very impulsive, and categories with ratings less than or equal to 4 were considered planned. This resulted in 19 very-impulsive categories and 46 planned categories (out of 100 food categories in our sample). We ran the weighted-average unhealthiness models for the two sets of categories separately. Consistent with our prediction, there was a significant difference between the effects of mode of payment on unhealthy purchases for very impulsive and planned categories. The coefficient of credit cards was higher for very impulsive product categories $(\beta=.329)$ than for planned categories $(\beta=.138)$, and this difference was significant $(t=143.9, p<.01)$. The same was true for debit cards: $\beta=.326$ for very impulsive categories versus $\beta=.179$ for planned categories $(t=67.1, p<.01)$. These results show that the effect of card payment on the purchase of unhealthy products is stronger when the unhealthy products tend to be more impulsive.

\section{Discussion}

Several important conclusions emerge from this study. First, this study offers preliminary support for our hypothesis that painless card payments can weaken impulse control. We observe that consumers tend to have a larger proportion of food items pretested as impulsive and unhealthy in their shopping baskets when they pay by credit card than when they pay in cash. This result supports hypothesis 1 . Second, consistent with hypothesis 2 , this effect manifested for debit cards also; shoppers who used debit cards had a larger proportion of vice products in their baskets. The finding that debit and credit cards have the same effect, even though debit card payments are immediately charged to the con- sumer's bank account, suggests that it is not discounting of delayed payments but, rather, it is the abstract and emotionally inert nature of card payments that reduces the pain of payment. Finally, our hypothesis that card payments can increase unhealthy purchases hinges on the assumption that some food items that are commonly considered unhealthy also tend to elicit impulsive purchase decisions. The pretest reported in this study offers a robust test of this assumption. Across 100 food product categories that account for about two-thirds of the value of the food items included in a typical shopping basket, we find that perceived impulsivity and unhealthiness are highly correlated.

Although these results are consistent with our hypotheses, given the nature of the data in this study, we are unable to establish the direction of causality. We do not know whether the consumers make the decision about the mode of payment before adding the products to the basket or whether they decide about the mode of payment after adding the products to the basket. Further, it is likely that mode of payment is correlated with other unobserved variables that might be driving these effects. To test the causal role of pain of payment, we conducted three experiments. These experiments also test the underlying psychological mechanism and rule out some other alternative accounts.

\section{STUDY 2: MANIPULATING MODE OF PAYMENT}

In this study, we manipulated the mode of payment in a laboratory experiment holding all other elements constant. If we observe that paying by credit card increases the purchase of unhealthy-impulsive food items in such a setting, then we can uniquely attribute the observed effect to mode of payment. Participants in this experiment responded to a simulated shopping task and were presented with 10 virtue products that were pretested as less impulsive and healthy and 10 vice products that were pretested as more impulsive 
and unhealthy. Thus, this study used a 2 (payment mode: credit card vs. cash) $\times 2$ (product type: vice vs. virtue) mixed factorial design with 10 replicates each of vice and virtue products. Mode of payment was a between-subjects factor while product type was a within-subjects factor. Additionally, since this was a controlled laboratory experiment, we also measured and analyzed the response time for purchase decisions to get insights into the underlying process.

\section{Method}

Participants. One hundred and fifty-one undergraduate and graduate students (47\% women) from Cornell University participated in this study for a small sum of money.

Stimuli and Pretest. In this study, participants considered 20 food products, half of which were virtue products while the other half were vice products (see the appendix for the full list). To confirm that our manipulation of product types served the intended purpose, a pretest was conducted with 27 students who did not participate in the main experiment. Twelve subjects rated the impulsiveness $(1=$ impulsive purchase and $7=$ planned purchase), and 15 participants rated the healthiness $(1=$ unhealthy and $7=$ healthy) of 20 food products. The 10 products that we considered as vice products were perceived to be more impulsive $(M=2.68)$ than the products that we considered virtue products $(M=4.61 ; t(11)=7.01, p<.01)$. The vice products were also perceived to be less healthy $(M=2.11)$ than the virtue products $(M=5.44 ; t(14)=17.17, p<$ $.01)$. Further, the impulsivity ratings and the unhealthiness ratings of the products collected from two separate sets of participants were highly correlated $(r=.91, p<.01)$. This result corroborates our pretest results from study 1 and suggests that unhealthy products also tend to be impulsive.

Procedure. Participants were invited to participate in a "Food Shopping Study," which was ostensibly conducted by a large retail chain that was planning to open a store in the town, to understand what types of food consumers buy on a typical shopping trip. They were told to imagine that they were in this new grocery store. The study was administered on computers. All participants saw the 10 vice and 10 virtue food products, one at a time, with the impulsive and virtue products interspersed. The 20 products were ordered randomly using a random number generator and presented sequentially. The products were presented in the same random order to all the participants. On each screen, they saw the name of the product (e.g., "Oreo Cookies"), a picture of the product (approximately $2 \times 2$ centimeters), and its price. There were two response buttons at the bottom of the screen. One button had the picture of a shopping basket and was labeled "Add to Shopping Cart" while the other one was to continue shopping. Participants proceeded to the next screen at their own pace by clicking on one of the two buttons. The computer unobtrusively recorded the response time for each product.

The mode of payment was manipulated immediately be- fore the participants saw the products. Participants assigned to the credit card condition saw the logos of four credit card companies-MasterCard, Visa, Discover, and American Express - accompanied by the statement "The store accepts all major credit cards." Such signs are usually displayed at the entrance of most retail stores in the United States. Participants assigned to the cash only condition were informed that the new store accepts only cash payments; credit cards or checks were not accepted at this store.

\section{Results}

Vice Products in Shopping Basket. For each participant, we computed the number of virtue and the number of vice products in the shopping basket. These measures were submitted to a $2 \times 2$ mixed factorial ANOVA with mode of payment (credit card vs. cash) as a between-subjects factor and type of product (vice vs. virtue) as a withinsubjects factor. The main effect of the type of product $(F(1,149)=43.92, p<.01)$ was qualified by a significant mode-of-payment by type-of-product interaction $(F(1,149)$ $=4.52, p=.035)$. There were more vice products in the basket when the mode of payment was credit card $(M=$ $2.85)$ than when the mode of payment was cash $(M=2.02$; $F(1,149)=6.15, p=.01)$. Further, the mode of payment did not affect the number of virtue products in the basket $\left(M_{\text {CreditCard }}=3.85\right.$ vs. $\left.M_{\text {Cash }}=3.97, F<1\right)$. We also ran a repeated-measures choice model and found that controlling for price differences of vice and virtue products and order of presentation did not mitigate the interaction effect of mode of payment and type of product. Thus, hypothesis 1 is supported.

We did a similar analysis for the values of vice and virtue products in the shopping basket. The pattern of results was similar to that reported above. Participants spent more on impulsive vice products when the mode of payment was credit card than when it was cash $\left(M_{\text {CreditCard }}=\$ 14.07\right.$ vs. $\left.M_{\text {Cash }}=\$ 9.89 ; F(1,149)=6.35, p<.01\right)$. However, the mode of payment did not affect the amount spent on virtue products in the basket $\left(M_{\text {CreditCard }}=17.50\right.$ vs. $M_{\text {Cash }}=17.43$; $F<1)$. The pattern of means is depicted in figure 1 .

Response Time for Purchase Decisions. To test our assumption that purchase decisions for vice products are spontaneously elicited, we analyzed the response time for participants' purchase decisions. We computed the logarithmic transforms of response times in milliseconds and removed outliers that were more than 3 standard deviations away from the mean. Since the order of presentation was a significant predictor of response time and accounted for a large proportion of the variance, the analysis was done using an ANCOVA to control for the effects of order. The logtransform of response time was submitted to a mixed factorial ANCOVA with mode of payment (credit card vs. cash) as a between-subjects factor, type of product (virtue vs. vice) as a within-subjects factor, and order of presentation as a covariate. Only the main effects of the order of presentation $(F(1,2,849)=472.63, p<.01)$ and the type of product 
FIGURE 1

THE EFFECT OF CREDIT CARDS ON IMPULSIVE PURCHASE DECISIONS (STUDY 2)

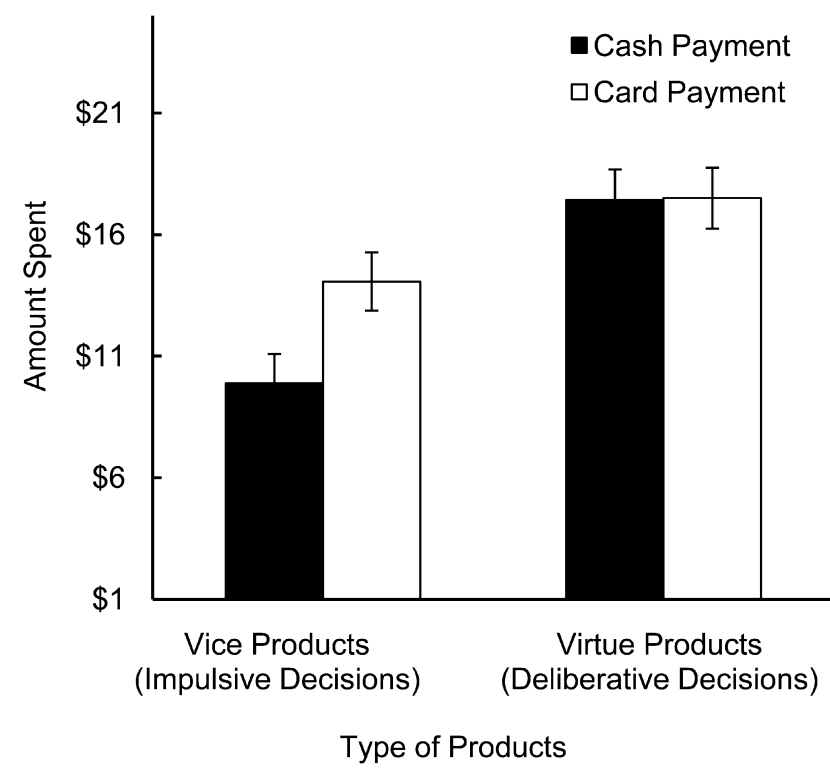

NotE.-Vice products are unhealthy food items purchased impulsively, while virtue products are healthy food items purchased after deliberative evaluations.

were significant $(F(1,149)=55.27, p<.01)$. Participants took less time to decide about vice products $(M=574$ milliseconds per product) than about virtue products $(M=$ 619 milliseconds per product). Neither the effect of mode of payment $(F<1)$ nor its interaction with type of product was significant $(p>.23)$. Although response time patterns are not conclusive evidence for the underlying process, these results are consistent with our predictions. These response time results suggest that purchase decisions for vice products were more spontaneous than those for virtue products.

\section{Discussion}

These results from the laboratory study support our hypothesis (hypothesis 1) that paying by credit card increases the proportion of impulsive vice products in the shopping basket. Participants assigned to the credit card condition were more likely to buy food products that were rated as impulsive even though these food items also had low healthiness ratings. However, the mode of payment did not affect purchase decisions of virtue products that were based on deliberative decisions. Together, studies 1 and 2 offer convergent evidence that mode of payment can weaken impulse control and thus increase purchases of unhealthy food items.

However, this study does not clarify why mode of payment influences the purchase of unhealthy food items. Our conceptualization assumes that the observed effect is caused by the interplay of the positive and negative emotional responses elicited by impulsive products and the pain of paying in cash, respectively. Cash payments are painful, and card payments are relatively painless. The negative emotion elicited by cash payments counters the positive emotion elicited by impulsive products and thus facilitates impulse control. In the following experiment, we directly test this account. We also test whether the reduced pain of payment in the credit card condition is due to inattention to prices.

\section{STUDY 3: MEDIATION BY PAIN OF PAYMENT}

This study replicates and extends the results from the previous experiment. This study was designed with three objectives in mind. First, to test the robustness of our results, instead of using students as participants, we gathered responses from a more representative sample of consumers from an online panel. The present experiment was administered as an online study by an independent market research firm to respondents in their online panel. Second, we included questions to measure the pain elicited by the mode of payment. We tested whether this pain of payment mediates the effect of mode of payment on the purchase of impulsive vice food items. If pain of payment mediates the effect of mode of payment on vice purchases but not on virtue products, then this moderated mediation would be direct evidence for the proposed account.

Third, we tested whether inattention to prices plays a role in reducing pain of payment for credit card users. Do credit card users experience less pain because they do not pay attention to prices? It is likely that credit card users pay less attention to prices, and this inattention to prices might reduce their pain of payment. If this is the case, then credit card users should be less accurate in recalling the amount of money they spent on the shopping trip in a surprise recall task. Alternatively, is credit card a less vivid and more emotionally inert medium that does not elicit the same pain of payment as cash does? This account posits that even when they carefully process the prices, credit card users do not experience the same pain of paying as consumers who use cash. To test these competing accounts, we asked participants to estimate their expenses in a surprise recall task.

\section{Method}

Participants. We used the paid service of an online market research firm to collect data for this experiment. Participants were consumers who were enrolled in the panel of an online market research firm (Qualtrics) for monetary benefits. One hundred and twenty-five participants $(48 \%$ women) completed the online questionnaires. One participant's responses were inconsistent and therefore excluded from the analyses. The average age of participants was 42 , and $78 \%$ of them had a household income of $\$ 30,000$ or more per annum. 
Procedure. The experiment used the same mixed factorial design as that in the previous study: 2 (payment mode: credit card vs. cash) $\times 2$ (product type: vice vs. virtue) design with 10 replicates of each product type. The questionnaire was created using an online software package. This software randomly assigned the participants to one of the two between-subjects conditions, that is, cash or credit card. The cover story, the stimuli, and the simulated shopping format used in this experiment were identical to those in the previous laboratory experiment. However, unlike the previous study, in this study, each participant saw a different random order of presentation of the 20 products. Further, several additional variables designed to measure the process were added to the questionnaire after the shopping task.

Attention to Price. Immediately after the shopping task, participants were asked to recall from memory how many items they included in the shopping basket and how much money they spent on the items put in the shopping basket. Participants were prevented from accessing the previous screens on which they made the shopping decisions; therefore, they had to make these estimates based on the prices of the products in their memory.

Pain of Payment. Then participants were asked to indicate how they felt about spending money during the shopping trip using two distinct scales. The first scale measured pain using a nonverbal faces scale. Specifically, they responded to the following question: "A store's payment policy can influence how consumers feel while spending money. How did you feel about spending money on this shopping trip?" Participants indicated their responses on a 5-point nonverbal faces pain scale with a sad face $(\dot{\theta})$ at the lower end of the scale and a happy face (;) at the higher end of the scale. The responses in this scale were reverse coded such that a higher number on this scale indicated more pain of payment. Subsequently, to interpret their responses to the nonverbal scale, they were shown a list of negative feelings and were asked to check all the words that described their feelings. Participants saw eight words: Irritated, Restricted, Annoyed, Powerless, Controlled, Suffocated, Inhibited, and None of the above. For each participant, we computed the number of negative feeling words that were checked.

Regret Spending Money. Subsequently, participants were asked to indicate to what extent they would regret spending money on food items if they were to purchase the food items. This measure was collected for all 20 products, one at a time. For each of the 20 products, they predicted their regret on a 5-point scale anchored at $1=$ Definitely not regret spending money on this item and $5=$ Definitely regret spending money on this item.

Healthiness of Food. Participants were asked to rate each of the 20 food items on healthiness, one at a time. Participants rated each product on a 5-point scale anchored at $1=$ Unhealthy and $5=$ Healthy. Finally, participants were asked to submit demographic and lifestyle information such as gender, age, household income, diet control behavior, and whether they had a medical condition that restricted their diet.

\section{Results}

Vice Products in Shopping Basket. As in the previous study, for each participant we computed the total number of virtue and vice products in the shopping basket. This measure was submitted to a $2 \times 2$ mixed factorial ANCOVA with mode of payment (credit card vs. cash) as a betweensubjects factor and type of product (virtue vs. vice) as a within-subjects factor. Since the data were collected from a heterogeneous sample of consumers, some of the demographic variables (diet control habits, medical condition, and household income) and their interactions with type of product were entered as covariates in this mixed model. The main effect of the mode of payment $(F(1,119)=4.04, p$ $=.046)$ was qualified by a significant mode-of-payment by type-of-product interaction $(F(1,119)=4.46, p=.036)$. There were more unhealthy impulsive items in the basket when the mode of payment was a credit card $(M=2.90)$ than when the mode of payment was cash $(M=1.73$; $F(1,119)=7.60, p<.01)$. Further, the mode of payment did not affect the number of virtue items in the basket $\left(M_{\text {CreditCard }}=3.31\right.$ vs. $\left.M_{\text {Cash }}=2.96, F<1\right)$. These results show that the findings in the previous study hold even with a more representative sample and thus support hypothesis 1 .

We did a similar analysis for the values of virtue and vice products in the shopping basket. The pattern of results was similar to that reported above. Participants spent more on vice products when the mode of payment was a credit card than when it was cash $\left(M_{\text {CreditCard }}=\$ 14.2\right.$ vs. $M_{\text {Cash }}=\$ 8.2$; $F(1,119)=8.06, p<.01)$. However, the mode of payment did not affect the amount spent on virtue products in the basket $\left(M_{\text {CreditCard }}=14.3\right.$ vs. $\left.M_{\text {Cash }}=12.5 ; F<1\right)$.

Pain of Payment. Participants' responses to the facespain question and the negative feelings word-list question were submitted to a one-way ANOVA. Participants in the cash condition reported greater feelings of pain of payment $\left(M_{\text {CreditCard }}=2.67\right.$ vs. $M_{\text {Cash }}=3.36 ; F(1,122)=13.35, p$ $<.01)$ and used more negative feeling words to describe their feeling $\left(M_{\text {CreditCard }}=0.77\right.$ vs. $M_{\text {Cash }}=1.30 ; F(1,122)$ $=6.42, p=.012$ ) than those in the credit card condition.

Moderated Mediation: Pain Mediates the Effect of Cash. Our conceptualization predicts that pain of payment will mediate the effect of mode of payment on impulsive products, but not virtue products. To test this moderated mediation hypothesis, we ran a series of regressions recommended by Muller, Judd, and Yzerbyt (2005). A schematic summary of the mediation model is presented in figure 2 . In the regressions, the cash payment condition was coded as 1 and the credit card condition as 0 . Mode of payment was a significant predictor of the number of impulsive products in the shopping basket $(\beta=-1.1, p<.01)$. Mode of payment also predicted pain of payment $(\beta=.69, p<.01)$. 
FIGURE 2

PAIN OF PAYMENT MEDIATES THE EFFECT OF CASH PAYMENTS ON IMPULSE CONTROL (STUDY 3)

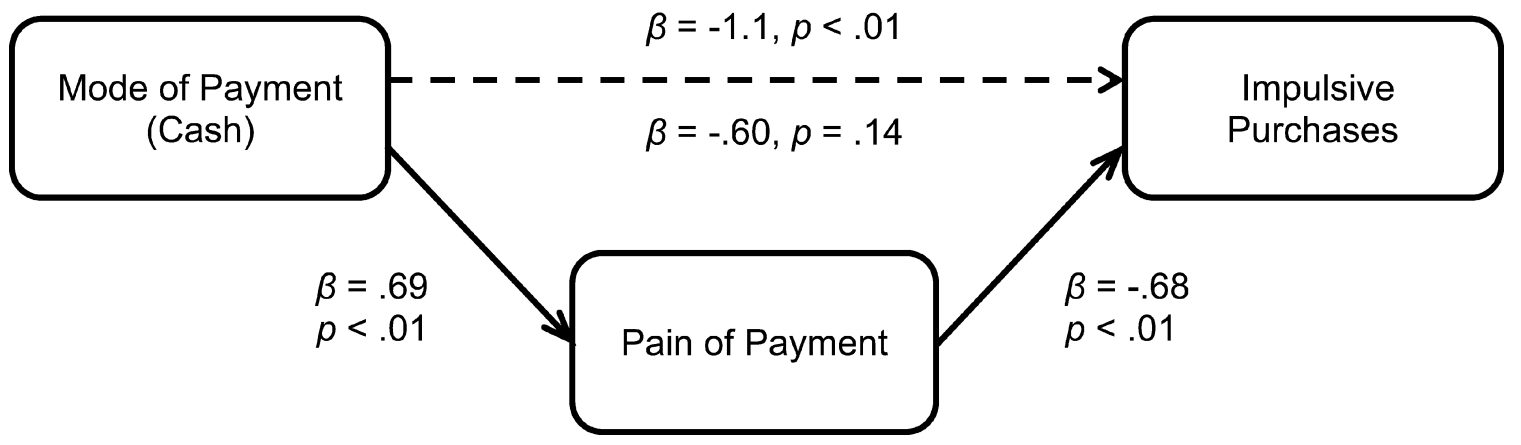

Further, pain of payment was a significant predictor of the number of impulsive products in the shopping basket $(\beta=$ $-.77, p<.01)$. However, when both pain of payment and cash payment were entered as predictors in the same model, the effect of cash payment was no longer significant $(\beta=$ $-.60, p=.14$ ), but the effect of pain of payment continued to be significant $(\beta=-.68, p<.01)$. A Sobel test confirmed the mediation $(z=-2.61, p<.01)$. However, these mediation results did not hold for virtue products. Thus, these moderated mediation results support our conceptualization that pain of paying in cash selectively reduces the proportion of vice products in the shopping basket.

Attention to Price. To test whether participants paid attention to the price of the products that they were putting into the shopping basket, they were asked to recall the total amount of money they spent on the shopping trip. Participants in the credit card condition reported spending more money than those in the cash condition $\left(M_{\text {CreditCard }}=\$ 30.6\right.$ vs. $\left.M_{\text {Cash }}=\$ 22.1\right)$, and these amounts were quite close to the actual amount that they spent $\left(M_{\text {CreditCard }}=\$ 28.5 \mathrm{vs}\right.$. $M_{\text {Cash }}=\$ 20.7$ ). (This is the total amount, that is, the sum of the amounts spent on vice and virtue products.) To test whether the attention to price varied across the two conditions, we computed the difference between the reported amount and the actual value of the products in the basket for each participant and submitted this measure to a oneway ANOVA. The values of this recall accuracy measure did not change across the two modes of payment, $F<1$. These results suggest that the painlessness of paying by credit card is not due to price neglect. Even when participants pay attention to price, paying by credit card reduces the pain of payment.

Perceived Healthiness. For each participant, we computed the average healthiness rating of the 10 virtue products and the average healthiness ratings of the 10 impulsive products. These two measures were submitted to a $2 \times 2$ mixed factorial ANOVA with mode of payment (credit card vs. cash) as a between-subjects factor and type of product (virtue vs. vice) as a within-subjects factor. Only the main effect of type of product was significant. As expected, participants perceived the 10 vice products to be less healthy than the 10 virtue products $\left(M_{\text {Vice }}=2.01\right.$ vs. $M_{\text {Virtue }}=4.07 ; F(1,122)$ $=528.1, p<.01)$. This result clearly shows that participants randomly assigned to the credit card payment condition bought more impulsive products despite being aware that these products were unhealthy.

Regret Spending Money. The anticipated regret on spending money on the two types of products was submitted to a similar analysis. We computed the average regret ratings for the 10 virtue products and the average regret ratings for the 10 impulsive products. These two measures were submitted to a $2 \times 2$ mixed factorial ANOVA with mode of payment (credit card vs. cash) as a between-subjects factor and type of product (virtue vs. vice) as a within-subjects factor. The main effect of type of product was significant; as expected, participants reported that they will experience more regret spending money on vice products than on the virtue products $\left(M_{\text {Vice }}=3.45\right.$ vs. $M_{\text {Virtue }}=2.81 ; F(1,122)$ $=41.75, p<.01)$. Further, the main effect of mode of payment was also significant. Participants reported that they will experience greater regret in spending money when they pay in cash than when they pay by credit cards $\left(M_{\text {Cash }}=\right.$ 3.34 vs. $\left.M_{\text {CreditCard }}=2.92 ; F(1,122)=7.39, p<.01\right)$. The two-way interaction was not significant, $F<1$. These results are important because they show that participants regret impulsively spending money on unhealthy food products. Impulsive purchases of unhealthy food products seem to be made on momentary feelings rather than on deliberative consideration of consequences of the consumption.

\section{Discussion}

These results are useful in several ways. First, we replicate our basic effect-credit card payments can increase consumption of unhealthy products-using a more representative sample of consumers. This shows that the results observed in study 2 cannot be attributed to idiosyncratic 
behavior of the student population. These results also lend more credibility to the results in (field) study 1 with a similar profile of consumers. Second, and more important, these results offer insights into the underlying process. We use the pain scale to measure the pain of payment and demonstrate that this pain mediates the effect of mode of payment. Thus, this study tests and finds support for the central thesis proposed in this paper that pain of payment plays a beneficial functional role in impulse control. Consumers can control their impulsive purchases by deciding to use cash instead of credit cards.

We find that paying by credit cards reduced pain of payment even when these participants were paying attention to prices. Note that we do not rule out the possibility that credit cards might induce price neglect. Whether or not consumers will accurately recall prices is contingent on several factors, including the design of the experiment. Indeed, it is likely that in some situations consumers might simply neglect prices when they pay by credit cards. The present results should be interpreted to imply that even in a situation where participants are carefully paying attention to prices, credit cards can reduce pain of payment, and this, in turn, can weaken impulse control. Furthermore, the alleviation of pain of payment caused by using less vivid and emotionally more inert modes of payment cannot be compensated by paying closer attention to prices.

Finally, consistent with Ubel's (2009) suggestion, these results suggest that the propensity to buy more impulsive products might not be based on justifiable reasoning. Participants unambiguously acknowledged that the impulsive products were unhealthy and that they would experience regret after purchasing these products. Yet, when they were paying by credit cards they were more inclined to buy such products. These results, thus, suggest that participants' purchase decisions in this experiment were influenced by the interplay of the momentary experiences elicited by the pain of payment and impulsive urges. In the following study, we seek further support for this conceptualization.

\section{STUDY 4: TIGHTWADS AND SPENDTHRIFTS}

Rick et al. (2008) have argued that individuals differ in their chronic propensity to experience pain of payment. Tightwads experience more pain than spendthrifts. Our conceptualization suggests that the effect of cash on impulse control will be stronger for tightwads than for spendthrifts (hypothesis 3) because they will experience greater pain. The present study tests this hypothesis.

\section{Method}

One hundred and twenty-five undergraduate students (37\% women) from the State University of New York, Binghamton, participated in this online experiment for partial course credit. The experiment was administered using the same software as in the previous study. The cover story, stimuli, and procedure were identical to the previous ex- periment. After the simulated shopping task, participants were asked to complete the four-item Spendthrift-Tightwad (ST-TW) scale developed by Rick et al. (2008). This scale comprises four items that measure respondents' spending habits on their usual shopping trips. A higher score on this scale indicates that the respondent experiences less pain of payment and is a spendthrift. Before completing this scale, participants were explicitly instructed that the questions on this scale refer to their usual shopping behaviors.

\section{Results}

Vice Products in Shopping Basket. Participants' responses to the four-item scale were combined to form a composite ST-TW index. The scores on the ST-TW scale did not change across the two mode-of-payment conditions $(p>.20)$. As in the previous two studies, for each participant we computed the total number of virtue and vice products in the basket. This measure was submitted to a mixed factorial ANCOVA with three factors: mode of payment (credit card vs. cash) as a between-subjects factor, type of product (virtue vs. vice) as a within-subjects factor, and the ST-TW scale value as a continuous variable. As in the previous study, some of the demographic variables (diet control habits, medical condition, and household income) and their interactions with type of products were entered as covariates in this mixed model. The main effects of type of product $(F(1,118)=7.15, p<.01)$, and the ST-TW scale value $(F(1,118)=7.42, p<.01)$ were significant. Further, as in the previous studies, the mode-of-payment $\times$ type-of-product interaction was significant $(F(1,118)=4.29, p=.04)$. More important, the three-way interaction was also significant $(F(1,118)=4.11, p=.045)$. A similar analysis on the amount of money spent on vice and virtue products yielded convergent results; the main effects ( $p$ 's $<.05)$, the two-way interaction $(F(1,118)=5.00, p=.027)$, and the three-way interaction were significant $(F(1,118)=4.33, p$ $=.039)$.

To make sense of this three-way interaction, following Rick et al.'s (2008) approach, we split the participants into three almost equal groups based on the scores on the STTW scale. The group with the lower scores on this scale was labeled as Tightwads, the one with the higher scores as Spendthrifts, and those with intermediate scores as Unconflicted. We then computed simple contrasts to test the effect of credit cards on the purchase of vice and virtue products for each of these three groups. The pattern of means for the two groups with extreme scores-Spendthrifts and Tightwads - is shown in figure 3. Mode of payment had a significant effect on Tightwads' purchase decisions; they were more likely to buy impulsive products when paying by credit card $(M=\$ 12.8)$ than when they had to pay in cash $(M=\$ 5.6 ; F(1,116)=6.67, p=.01)$. However, as predicted, mode of payment did not influence impulsive purchase decisions of Spendthrifts and Unconflicted participants $\left(F^{\prime} s<1\right)$. Further, for all three groups of participants, mode of payment did not influence purchase decisions of 
FIGURE 3

THE EFFECT OF PAIN OF PAYMENT ON TIGHTWADS AND SPENDTHRIFTS (STUDY 4)

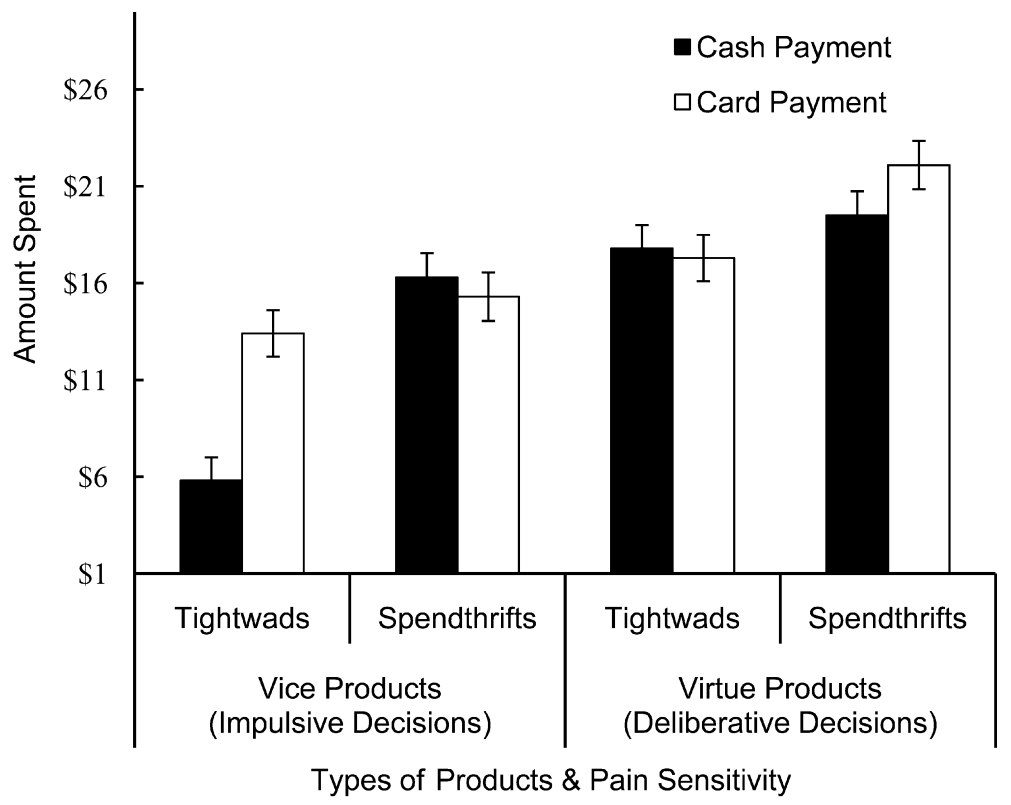

NOTE.-Vice products are unhealthy food items purchased impulsively, while virtue products are healthy food items purchased after deliberative evaluations.

virtue products $(F ' s<1)$. A spotlight analysis at one standard deviation below mean of the ST-TW scale showed a significant difference such that Tightwads were more likely to spend on unhealthy products with credit cards than with cash $(\beta=5.41 ; t=2.32, p=.02)$. But the effects of mode of payment were not significant at the mean level of the ST-TW scale $(p>.36)$ and one standard deviation above the mean $(p>.28)$. These results support hypothesis 3 and our conceptualization that the painless nature of credit cards weakens impulse control.

\section{GENERAL DISCUSSION}

\section{Summary and Implications}

Four empirical studies were conducted to test the influence of mode of payment on the proportion of unhealthy food products in consumers' shopping baskets. The results from all these studies offer convergent support for our hypothesis that card payments increase the purchase and, presumably, the consumption of unhealthy food products. Our conceptualization is based on the premise that when consumers encounter vice products-such as cookies, cakes, and pies - the emotive imagery and associated desire trigger impulsive purchase decisions. These visceral factors entice them to include such vice products in their shopping baskets, even though they consider such products to be unhealthy.
Pain of payment can curb the impulsive responses and thus reduce the purchase of such vice products. Since paying in cash feels more painful than paying by credit or debit cards, paying in cash can reduce the purchase of unhealthy food items. To test this hypothesis, in study 1 we analyzed the shopping baskets of 1,000 households over a period of 6 months. We found that shopping baskets had a larger proportion of impulsive and unhealthy food items when shoppers paid by credit or debit cards than when they paid in cash. Studies 2-4 replicated this effect using samples from different populations and offered insights into the underlying process. Study 2 showed that although participants in the cash payment condition purchased fewer vice products, they did not take more time to make purchase decisions. This result suggests that the effect of cash payments is caused by spontaneous pain of payment rather than by deliberative reasoning. The moderated mediation analyses in study 3 offered direct evidence for the mediating effect of pain of payment. In study 4, using the spendthrift-tightwad scale, we found that individual differences in sensitivity to pain of payment can moderate the effect of mode of payment. Together, these studies persuasively implicate pain of payment as the mechanism that underlies the vice-regulation effect of cash payments.

These results have implications for consumer welfare. In the popular press as well as in academic publications, the growing obesity problem and its economic consequences 
have been attributed to consumers' failures to control impulsive urges (Ubel 2009). Further, researchers have identified several factors that make impulse control a challenging goal for consumers. Given this background, the finding that at least some consumers might be able to curb their impulsive urges by paying in cash is of substantive importance.

The results also augment our knowledge of how mode of payment influences buyers' behavior. Although several studies have shown that credit cards influence buyer behavior, how it does this has been a matter of debate. It has been suggested that people are conditioned to spend more with credit cards (Feinberg 1986; McCall and Belmont 1996). The conditioning account for mode-of-payment effects does not grant any role to affective processes. In contrast to this view, Prelec and Loewenstein (1998) proposed that credit cards reduce the pain of payment. The present research offers direct evidence for Prelec and Loewenstein's visceralfactors account for mode of payment effects. We find that experienced pain of payment mediates the effect of cash payments on impulse control (see fig. 2) and that chronic sensitivity to pain of payment moderates the effect (see fig. 3 ). Further, we show that the effect of pain of payment is contingent on whether the purchase decision is made impulsively or deliberately.

Our results also suggest that the painlessness of paying by credit card is not due to price neglect. Participants in study 3 paying by credit cards did not experience pain even though they were paying attention to prices, as confirmed by the surprise recall task. This result is important because several consumers might believe that they can curb their impulsive behavior by paying attention to prices. Our results suggest that such beliefs might be misplaced. Consumers experience less pain when they use less vivid and emotionally more inert modes of payment and succumb to their impulsive urges, and this effect may not be mitigated by paying closer attention to prices.

\section{Unaddressed Questions}

The results from our studies also raise several unaddressed questions that could be fruitful avenues for future research. We identify two such questions here. First, this research adds to a burgeoning body of literature that offers evidence that emotional sensitivity to modes of payment can vary (Mishra et al. 2006; Prelec and Loewenstein 1998; Raghubir and Srivastava 2008, 2009). However, it is not clear why this happens. Why are card payments emotionally more inert than cash payments? One possibility is that the pain of payment is a function of the abstractness of the transaction. Card payments might be construed abstractly, whereas cash might be construed concretely in consumers' minds. Parting with a hundred dollar bill is a very vivid and concrete action. However, charging $\$ 100$ to one's credit or debit card is an abstract and less vivid action. Just as a concrete and vivid mental representation of "a can of Coke" is more likely to elicit a stronger visceral response than the abstract construal of "a beverage," abstract construal of parting with money is likely to be less painful than concrete construal of parting with the same amount of money. An empirical test of this hypothesis might reveal new insights about the role of abstract and concrete construals in mode of payment effects.

Second, it might be useful to compare and contrast visceral regulators such as cash against willpower. Although in this paper we do not directly pit visceral regulation against willpower, previous research suggests that visceral regulators are likely to be more effective in self-control because willpower gets depleted (Vohs and Heatherton 2000) and requires cognitive capacity (Shiv and Fedorikhin 1999). However, despite the obvious advantages of visceral regulators, consumers might tend to rely on their willpower based on the potentially misplaced belief that willpower is as effective as visceral regulators. Preliminary evidence for this proposition comes from the anecdotal observation that although over $60 \%$ of American adults are overweight or obese, only $14 \%$ of American consumers use cash payments on their shopping trips. Examining when visceral regulators are likely to be more effective than willpower and investigating whether people who are more effective at impulsecontrol tend to delegate the control function to visceral regulators could be fruitful avenues for future research.

\section{APPENDIX}

Vice products (Impulsive-Unhealthy): Chips Ahoy Chocolate Chip Cookies \$3.91, Coca Cola Classic \$4.99, Ghirardelli Hot Cocoa \$6.39, Little Debbie Muffins-Banana Nut \$3.85, Mrs. Smith's Apple Pie \$5.85, Mrs. Smith's Pumpkin Pie \$5.85, Oreo Cookies-Chocolate Sandwich \$3.71, Oreo Cookies-Golden Sandwich \$3.71, Sara Lee Cheesecake \$8.99, Drake's Coffee Cakes \$5.15

Virtue products (Deliberative-Healthy): Aquafina Pure Water-six pack \$6.99, Arnold/Brownberry 100\% Whole Wheat Bread \$3.85, Bush's Baked Bean \$2.19, Cheerios Cereal-Honey Nut \$7.95, Del Monte Diced Peaches \$3.95, Health Valley Granola \$4.59, Kashi Go Lean Crunch Cereal \$3.85, Quaker Oatmeal \$5.39, Special K Cereal \$5.15, Yoplait $99 \%$ Fat Free Yogurt $\$ 1.45$

\section{REFERENCES}

Ainslie, Andrew and Peter E. Rossi (1998), "Similarities in Choice Behavior across Product Categories," Marketing Science, 17 (2), 91-106.

Baumeister, Roy F. (2002) "Yielding to Temptation: Self-Control Failure, Impulsive Purchasing, and Consumer Behavior," Journal of Consumer Research, 28 (4), 670-76.

Bell, David R. and James M. Lattin (1998), "Shopping Behavior and Consumer Preference for Store Price Format: Why 'Large Basket' Shoppers Prefer EDLP,” Marketing Science, 17 (1), 66-88.

Cheema, Amar and Dilip Soman (2008), "The Effect of Partitions on Controlling Consumption," Journal of Marketing Research, 45 (December), 665-75.

Feinberg, Richard A. (1986), "Credit Cards as Spending Facilitating Stimuli: A Conditioning Interpretation," Journal of Consumer Research, 13 (3), 348-56. 
Hoch, Stephen J. and George F. Loewenstein (1991), "Time-Inconsistent Preferences and Consumer Self-Control," Journal of Consumer Research, 17 (4), 492-507.

Humphrey, David B. (2004), "Replacement of Cash by Cards in U.S. Consumer Payments," Journal of Economics and Business Research, 56 (4), 211-25.

Khan, Uzma and Ravi Dhar (2006), "Licensing Effect in Consumer Choice," Journal of Marketing Research, 43 (May), 269-66.

Kivetz, Ran, and Anat Keinan (2006), "Repenting Hyperopia: An Analysis of Self-Control Regrets," Journal of Consumer Research, 33 (September), 273-82.

Kross, Ethan, Ozlem Ayduk, and Walter Mischel (2005), "When Asking 'Why' Doesn't Hurt: Distinguishing Rumination from Reflective Processing of Negative Emotions," Psychological Science, 16, 709-15.

Loewenstein, George (1996), "Out of Control: Visceral Influences on Behavior," Organizational Behavior and Human Decision Processes, 65 (3), 272-92.

McCall, Michael and Heather J. Belmont (1996), "Credit Card Insignia and Restaurant Tipping: Evidence for an Associative Link," Journal of Applied Psychology, 81 (5), 609-13.

Metcalfe, Janet and Walter Mischel (1999), "A Hot/Cool System Analysis of Delay of Gratification: Dynamics of Willpower," Psychological Review, 106 (January), 3-19.

Mishra, Himanshu, Arul Mishra, and Dhananjay Nayakankuppam (2006), "Money: A Bias for the Whole," Journal of Consumer Research, 32 (March), 541-49.

Muller, Dominique, Charles M. Judd, and Vincent Y. Yzerbyt (2005), "When Moderation Is Mediated and Mediation Is Moderated," Journal of Personality and Social Psychology, 89 (6), 852-63.

Nilson Report (2007), The Nilson Report, Trade Publication on consumer payment systems, Issue 890, October.

Ogden, Cynthia L., Margaret D. Carroll, Lester R. Curtin, Margaret A. McDowell, Carolyn J. Tabak, and Katherine M. Flegal (2006), "Prevalence of Overweight and Obesity in the United States, 1999-2004," Journal of the American Medical Association, 295 (13), 1549-55.

Prelec, Drazen and George Loewenstein (1998), "The Red and the Black: Mental Accounting of Savings and Debt," Marketing Science, 17 (1), 4-28.

Puri, Radhika (1996), "Measuring and Modifying Consumer Impulsiveness: A Cost-Benefit Accessibility Framework," Journal of Consumer Psychology, 5 (2), 87-113.

Raghubir, Priya and Joydeep Srivastava (2008), "Monopoly Money: The Effect of Payment Coupling and Form on Spend- ing Behavior," Journal of Experimental Psychology: Applied, 14 (3), 213-25.

(2009), "The Denomination Effect," Journal of Consumer Research, 36 (4), 701-13.

Raghunathan, Rajagopal, Rebecca Walker-Naylor, and Wayne D. Hoyer (2006), "The Unhealthy = Tasty Intuition and Its Effects on Taste Inferences, Enjoyment, and Choice of Food Products," Journal of Marketing, 70 (4), 170-84.

Ramanathan, Suresh and Geeta Menon (2006), "Time-Varying Effects of Chronic Hedonic Goals on Impulsive Behavior," Journal of Marketing Research, 43 (4), 628-41.

Rick, Scott I., Cynthia E. Cryder, and George Loewenstein (2008), "Tightwads and Spendthrifts," Journal of Consumer Research, 34 (April), 767-82.

Rook, Dennis (1987), “The Buying Impulse,” Journal of Consumer Research, 14 (September), 189-99.

Scott, Maura L., Stephen M. Nowlis, Naomi Mandel, and Andrea C. Morales (2008), "The Effects of Reduced Food Size and Package Size on the Consumption Behavior of Restrained and Unrestrained Eaters," Journal of Consumer Research, 35 (October), 391-405.

Shiv, Baba and Alexander Fedorikhin (1999), "Heart and Mind in Conflict: The Interplay of Affect and Cognition in Consumer Decision Making," Journal of Consumer Research, 26 (3), 278-92.

Soman, Dilip (2001), "Effects of Payment Mechanism on Spending Behavior: The Role of Rehearsal and Immediacy of Payments," Journal of Consumer Research, 27 (4), 460-74.

Soman, Dilip and Amar Cheema (2002), "The Effect of Credit on Spending Decisions: The Effect of Credit Limit and Credibility," Marketing Science, 21 (1), 32-53.

Ubel, Peter A. (2009), Free Market Madness, Boston: Harvard Business Press.

Vohs, Kathleen D. and Todd F. Heatherton (2000), "Self-Regulatory Failure: A Resource-Depletion Approach," Psychological Science, 11 (3), 249-54.

Wansink, Brian (2006), Mindless Eating-Why We Eat More than We Think, New York: Bantam-Dell.

Wansink, Brian and Pierre Chandon (2007), "The Biasing Health Halos of Fast-Food Restaurant Health Claims: Lower Calorie Estimates and Higher Side-Dish Consumption Intentions," Journal of Consumer Research, 34 (3), 301-14.

Wertenbroch, Klaus (1998), "Consumption Self-Control by Rationing Purchase Quantities of Virtue and Vice," Marketing Science, 17 (4), 1-10. 